\title{
Sustainable cardanol-based ionic surfactants
}

1 Ibrahima Faye PhD

Research Scientist, Institut Charles Gerhardt - UMR 5253 - Centre National de la Recherche Scientifique, Université de Montpellier, École Nationale Supérieure de Chimie de Montpellier, Montpellier, France

2 Vincent Besse PhD

Research Scientist, Institut Charles Gerhardt - UMR 5253 - Centre National de la Recherche Scientifique, Université de Montpellier, École Nationale Supérieure de Chimie de Montpellier, Montpellier, France
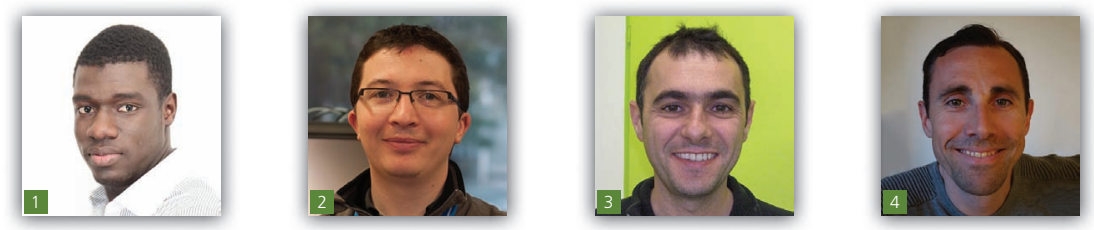

Alkylbenzenes are among the carbon chains most commonly used as a hydrophobic part to develop surfactants. In this paper, the authors present a sustainable alternative using cardanol. Cardanol is obtained by vacuum distillation of cashew nut shell liquid which is a non-edible oil directly extracted from the shell of the cashew nut, the fruit of the cashew tree. Three ionic surfactants based on cardanol were synthesized: a cationic, an anionic and a zwitterionic surfactant. An intermediate was first synthesized by nucleophilic substitution to generate a primary amine. Subsequently, this amine was used to open the cycles of trimethylammoniumglycidyl chloride and 1,3-propanesultone to obtain cationic and anionic surfactants, respectively. And, finally, the obtained cationic and anionic surfactants were coupled with 1,3propanesultone and trimethylammoniumglycidyl chloride, respectively, to give sulfobetaine surfactants. The surface activity and Krafft temperature were studied as a function of the salt concentration of the synthesized molecules.

\section{Introduction}

Surfactants are amphiphilic molecules composed of a hydrophobic part (the tail) and a hydrophilic group (the head). By their structure, they are able to lower the surface tension of a liquid or the interfacial tension between two liquids or between a liquid and a solid. ${ }^{1}$ They are among the most widespread and versatile chemical compounds used in the world. They are used in the pharmaceutical industry, cosmetics and toiletries. ${ }^{2}$ The surfactant market is expected to generate more than US $\$ 41$ billion of revenues in 2018 - translating to an average annual growth of $4.5 \%$. Most of the time, these surfactants are of petroleum origin and are not often biodegradable.

Because of the scarcity and high cost of petroleum resources and within the context of sustainable development, research themes are increasingly oriented toward the use of natural and renewable materials to produce environmentally friendly products and the chemistry of surfactants is not left behind. Cardanol, obtained by vacuum distillation of cashew nut shell liquid (CNSL), is a promising renewable resource. CNSL is directly extracted from the shell of the cashew nut, the fruit of the cashew tree, Anacardium occidentale. This tree is mainly grown in India and also in East Africa and Brazil.

CNSL constitutes nearly $25 \%$ of the total weight of the nut and is composed of anacardic acid (3-n-pentadecylsalicylic acid) and smaller amounts of cardanol (3- $n$-pentadecylphenol), cardol (5$n$-pentadecylresorcinol) and methylcardol (2-methyl-5- $n$ pentadecylresorcinol), the long aliphatic side-chain being saturated, monoolefinic (position 8), diolefinic (positions 8 and 11) and triolefinic (positions 8, 11 and 14), with an average value of two double bonds per molecule (Figure 1). The thermal treatment of cashew nuts and CNSL induces the partial decarboxylation of anacardic acid, which is completed by a subsequent distillation. ${ }^{3,4}$ The result is an industrial-grade cardanol in the form of a yellow oil containing mainly cardanol (about 90\%), with a small percentage of cardol and methylcardol. The total production of cardanol approaches an annual output of around $500000 \mathrm{t}^{5}$ The interesting structure of cardanol and its being naturally occurring and low cost make it increasingly used as a starting compound to design new materials. Cardanol is used as a precursor of functional small organic compounds and biobased polymer materials. ${ }^{4,6-8}$ Moreover, it finds wide applications such as plasticizers, antibacterial coatings and surfactants. ${ }^{9}$ Effective non-ionic, ${ }^{10,11}$ anionic ${ }^{12-16}$ and cationic $^{3,17,18}$ surfactants based on cardanol have been described in the literature. However, no paper reports the synthesis of zwitterionic surfactant from cardanol. Zwitterionic surfactants have excellent surface and interface properties, low irritation, good detergency and fine stability, and their solubility is less affected by $\mathrm{pH}$ than the solubility of anionic and cationic surfactants. Zwitterionic sulfobetaine surfactants have good compatibility and synergy with 

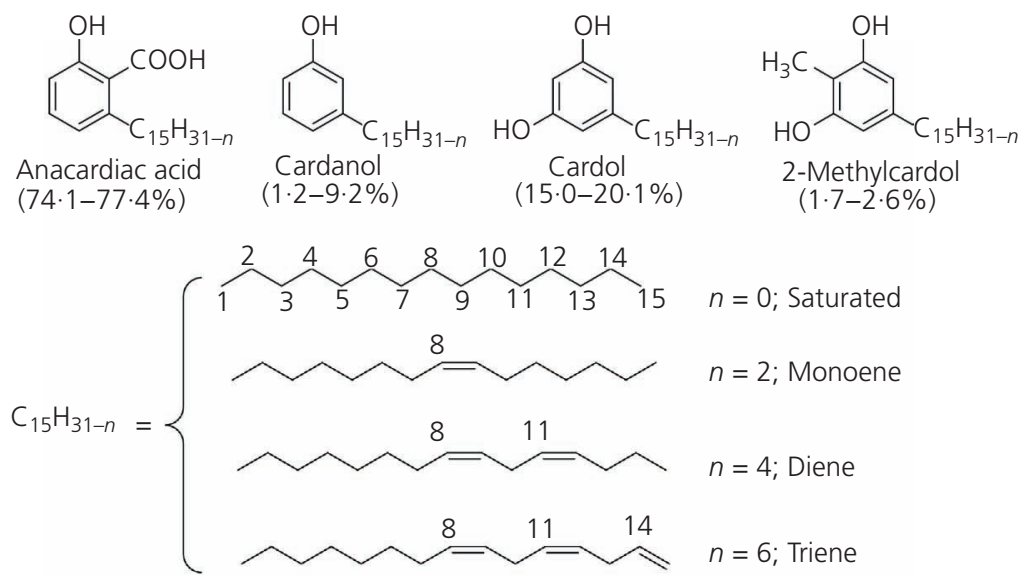

Figure 1. CNSL components

anionic surfactants. ${ }^{19,20}$ In addition, zwitterionic betaine surfactants have excellent performance for enhanced oil recovery. ${ }^{21}$

Cardanol-based anionic surfactants were generally synthesized by aromatic sulfonation of cardanol with excess sulfuric acid in halogenated solvents. The use of 1,3-propanesultone (PS) avoids reaction with concentrated sulfuric acid.

In this study, the authors report the synthesis of an anionic, a cationic and an amphoteric new surfactant based on cardanol, and their characterization by nuclear magnetic resonance (NMR). Their physicochemical proprieties such as critical micelle concentration $(\mathrm{CMC})$, surface tension at the $\mathrm{CMC}\left(\Upsilon_{\mathrm{CMC}}\right)$ and Krafft temperature were investigated.

Synthetic pathways have never been used on cardanol before and have made it possible to obtain the molecules with high yields. One of the original features of these synthesis procedures lies in the fact that the polar heads of the anionic and cationic synthesized surfactants are combined to form the polar head of the synthesized zwitterionic sulfobetaine surfactant; thus, the sulfonate is not linked with the quaternary ammonium.

\section{Experimental section}

\subsection{Materials}

Cardanol was provided by Cardolite Corporation (USA); sodium hydroxide $(\mathrm{NaOH})(>98 \%)$, trimethylammoniumglycidyl chloride $(>90 \%)$ and anhydrous magnesium sulfate $\left(\mathrm{MgSO}_{4}\right)$ were purchased from Sigma-Aldrich (France); 3-chloropropylamine hydrochloride (98\%) and PS (98\%) were obtained from Alfa Aesar (France). $\mathrm{N}, \mathrm{N}$ dimethylforamide and anhydrous methanol were purchased from VWR (France). All materials were used as received.

Proton $\left({ }^{1} \mathrm{H}\right)$ and carbon-13 $\left({ }^{13} \mathrm{C}\right)$ NMR analyses were performed in deuterated chloroform $\left(\mathrm{CDCl}_{3}\right)$ using a Bruker Advance $400 \mathrm{MHz}$ NMR spectrometer at a temperature of $25^{\circ} \mathrm{C}$.
Surface tension measurements were performed in $0.5 \mathrm{M}$ sodium chloride $(\mathrm{NaCl})$ in water using the pendant drop method with an OCA 15EC device from Apollo Instruments.

\subsection{Synthesis}

\subsubsection{Synthesis of 3-pentadecyl phenyl propanamine}

A detailed description of the synthesis of 3-pentadecyl phenyl propanamine (PPA) is as follows: $5 \mathrm{~g}(16.66 \mathrm{mmol})$ of cardanol, $2 \mathrm{~g}(50 \mathrm{mmol})$ of sodium hydroxide and $100 \mathrm{ml}$ of $\mathrm{N}, \mathrm{N}$ dimethylformamide were combined in a $250 \mathrm{ml}$, two-necked round-bottomed flask. Nitrogen was purged for $10 \mathrm{~min}$ into the reaction mixture. The mixture was stirred for $1 \mathrm{~h}$, and $4.3 \mathrm{~g}$ (33 mmol) of 3-chloropropylamine hydrochloride (98\%, SigmaAldrich) was added. The reaction mixture was stirred at room temperature for $36 \mathrm{~h}$. When the reaction was complete, the mixture was diluted with $100 \mathrm{ml}$ of ethyl acetate and washed three times with $50 \mathrm{ml}$ of deionized (DI) water and once with brine solution $(100 \mathrm{ml})$. The organic layer was dried with anhydrous magnesium sulfate and filtered. The filtrate was distilled under vacuum to recycle the ethyl acetate and to give $5.4 \mathrm{~g}$ of PPA as a yellow viscous oil (94\% yield). Successful production of PPA was determined using proton and carbon-13 NMR spectroscopy.

Proton NMR (400 MHz, deuterated chloroform, TMS): $\delta$ (parts per million (ppm)) 6.6-7.2 (m, 4H, aromatic $\mathrm{CH})$; 4.97-5.92 (m, $\left.4 \cdot 5 \mathrm{H},-\mathrm{CH}_{2} \mathrm{CH}=\mathrm{CHCH}_{2}-;-\mathrm{CH}_{2} \mathrm{CH}=\mathrm{CH}_{2}\right) ; 4.04$ (t, $2 \mathrm{H}$, $\left.-\mathrm{OCH}_{2} \mathrm{CH}_{2} \mathrm{CH}_{2} \mathrm{NH}_{2}-\right) ; 2.92$ (t, $2 \mathrm{H},-\mathrm{OCH}_{2} \mathrm{CH}_{2} \mathrm{CH}_{2} \mathrm{NH}_{2}$ ); $2 \cdot 7-2 \cdot 86$ $\left(2 \mathrm{H},=\mathrm{CHCH}_{2} \mathrm{CH}=\right) ; 2.55\left(\mathrm{t}, 2 \mathrm{H}, \mathrm{Ar}-\mathrm{CH}_{2} \mathrm{CH}_{2} \mathrm{CH}_{2}-\right) ; 2.02(\mathrm{~m}, 3 \mathrm{H}$, $\left.=\mathrm{CHCH}_{2} \mathrm{CH}_{2}-\right) ; 1.93\left(\mathrm{q}, 2 \mathrm{H},-\mathrm{OCH}_{2} \mathrm{CH}_{2} \mathrm{CH}_{2} \mathrm{NH}_{2}-\right) ; 1.6(\mathrm{~m}, 2 \mathrm{H}$, $\left.\mathrm{Ar}-\mathrm{CH}_{2} \mathrm{CH}_{2} \mathrm{CH}_{2}-\right) ; 1 \cdot 2-1 \cdot 45\left(\mathrm{~m}, 12 \mathrm{H},-\mathrm{CH}_{2} \mathrm{CH}_{2} \mathrm{CH}_{2}-\right) ; 0 \cdot 86-0.93$ (m, $1 \cdot 8 \mathrm{H},-\mathrm{CH}_{2} \mathrm{CH}_{3}$ ).

Carbon-13 NMR (400 MHz, deuterated chloroform, TMS): $\delta(\mathrm{ppm}) 158 \cdot 8(1 \mathrm{C}$, aromatic $\mathrm{CH}-\mathrm{O}) ; 144.6$ (1C, aromatic $\left.\mathrm{C}-\mathrm{CH}_{2}-\right) ; 136 \cdot 8 \quad\left(-\mathrm{CH}_{2} \mathrm{CH}=\mathrm{CH}_{2}\right) ; 130 \cdot 4-126 \cdot 8$ (1C aromatic, $-\mathrm{CH}_{2} \mathrm{CH}=\mathrm{CH}_{2}-\mathrm{CH}_{2} \mathrm{CH}=\mathrm{CHCH}_{2}-$ ); 120.97 (1C aromatic); 114.75 
(1C aromatic); 111.37 (1C aromatic); $65.38\left(-\mathrm{OCH}_{2} \mathrm{CH}_{2} \mathrm{CH}_{2} \mathrm{NH}_{2}-\right)$; $38.95\left(-\mathrm{OCH}_{2} \mathrm{CH}_{2} \mathrm{CH}_{2} \mathrm{NH}_{2}\right) ; \quad 36 \cdot 1 \quad\left(=\mathrm{CHCH}_{2} \mathrm{CH}=\right) ; \quad 31 \cdot 8-25 \cdot 7$ ( $\left.\mathrm{Ar}-\mathrm{CH}_{2} \mathrm{CH}_{2} \mathrm{CH}_{2-} ;-\mathrm{OCH}_{2} \mathrm{CH}_{2} \mathrm{CH}_{2} \mathrm{NH}_{2}-;-\mathrm{CH}_{2} \mathrm{CH}_{2} \mathrm{CH}_{2}-\right) ; 22 \cdot 7$ $\left(-\mathrm{CH}_{3} \mathrm{CH}_{2}-\right) ; 14 \cdot 15\left(\mathrm{CH}_{3}-\right)$.

\subsubsection{Synthesis of $N$-trimethylammoniumglycidyl-PPA}

$N$-trimethylammoniumglycidyl (TMAG)-PPA was synthesized using the epoxide ring-opening reaction. In a typical synthetic procedure, 1:1 1 mole ratio of PPA $(2 \cdot 8 \mathrm{mmol})$ and trimethylammoniumglycidyl chloride (TMAGC) $(3.08 \mathrm{mmol})$ were mixed at room temperature in anhydrous methanol $(35 \mathrm{ml})$ under nitrogen atmosphere and stirred at reflux temperature for $8 \mathrm{~h}$. After this, methanol was evaporated and the product was dissolved in chloroform and then washed three times with DI water. The organic layer was dried with magnesium sulfate and filtered. After evaporation of chloroform and then drying under vacuum, a yellow pasty product was obtained (96\% yield) and was analyzed by proton and carbon-13 NMR spectroscopy.

Proton NMR (400 MHz, deuterated chloroform, TMS): $\delta$ (ppm) 6.6-7.2 (m, 4H, aromatic $\mathrm{CH}) ; 4 \cdot 97-5 \cdot 92(\mathrm{~m}, 4 \cdot 5 \mathrm{H}$, $\left.-\mathrm{CH}_{2} \mathrm{CH}=\mathrm{CHCH}_{2}-;-\mathrm{CH}_{2} \mathrm{CH}=\mathrm{CH}_{2}\right) ; 4.37\left(\mathrm{~m}, 1 \mathrm{H},-\mathrm{CH}_{2} \mathrm{CH}-(\mathrm{OH})\right.$ $\left.\mathrm{CH}_{2}-\right) ; 3.98$ (t, $\left.2 \mathrm{H},-\mathrm{OCH}_{2} \mathrm{CH}_{2} \mathrm{CH}_{2} \mathrm{NH}-\right) ; 3.4-3.7$ (dd, $2 \mathrm{H}$, $\left.-\mathrm{CH}_{2} \mathrm{~N}\left(\mathrm{CH}_{3}\right)_{3}\right) ; 3 \cdot 37$ (s, 9H, $\left.-\mathrm{N}\left(\mathrm{CH}_{3}\right)_{3}\right) ; 2 \cdot 6-2 \cdot 8 \quad$ (m, 4H, $\left.-\mathrm{OCH}_{2} \mathrm{CH}_{2} \mathrm{CH}_{2} \mathrm{NH}-,=\mathrm{CHCH}_{2} \mathrm{CH}=\right) ; 2.55$ (t, $2 \mathrm{H}, \mathrm{Ar}-\mathrm{CH}_{2} \mathrm{CH}_{2} \mathrm{CH}_{2}-$ ); $2.02\left(\mathrm{~m}, 5 \mathrm{H},=\mathrm{CHCH}_{2} \mathrm{CH}_{2}-,-\mathrm{OCH}_{2} \mathrm{CH}_{2} \mathrm{CH}_{2} \mathrm{NH}-\right) ; 1.6(\mathrm{~m}, 2 \mathrm{H}$, $\left.\mathrm{Ar}-\mathrm{CH}_{2} \mathrm{CH}_{2} \mathrm{CH}_{2}-\right) ; 1 \cdot 2-1 \cdot 45\left(\mathrm{~m}, 12 \mathrm{H},-\mathrm{CH}_{2} \mathrm{CH}_{2} \mathrm{CH}_{2}-\right) ; 0 \cdot 86-0.93$ (m, $1 \cdot 8 \mathrm{H},-\mathrm{CH}_{2} \mathrm{CH}_{3}$ ).

Carbon-13 NMR (400 MHz, deuterated chloroform, TMS): $\delta(\mathrm{ppm}) 158.8(1 \mathrm{C}$, aromatic $\mathrm{CH}-\mathrm{O}) ; 144.6$ (1C, aromatic $\left.C-\mathrm{CH}_{2}-\right) ; 136 \cdot 8 \quad\left(-\mathrm{CH}_{2} \mathrm{CH}=\mathrm{CH}_{2}\right) ; 130 \cdot 4-126 \cdot 8 \quad(1 \mathrm{C}$ aromatic, $-\mathrm{CH}_{2} \mathrm{CH}=\mathrm{CH}_{2}-\mathrm{CH}_{2} \mathrm{CH}=\mathrm{CHCH}_{2}-$ ); 120.97 (1C aromatic); 114.75 (1C aromatic); 111.37 (1C aromatic); $69 \cdot 25\left(-\mathrm{CH}_{2}-\mathrm{N}\left(\mathrm{CH}_{3}\right)_{2}\right) ; 65 \cdot 38$ $\left(-\mathrm{OCH}_{2} \mathrm{CH}_{2} \mathrm{CH}_{2} \mathrm{NH}-\right) ; 64 \cdot 3(-\mathrm{CH}-\mathrm{OH}) ; 54.63\left(\mathrm{CH}_{3}-\mathrm{N}\right) ; 52.58$ $\left(-\mathrm{CH}_{2}-\mathrm{NH}-\right) ; 46 \cdot 56\left(-\mathrm{OCH}_{2} \mathrm{CH}_{2} \mathrm{CH}_{2} \mathrm{NH}-\right) ; 36 \cdot 1 \quad\left(=\mathrm{CHCH}_{2} \mathrm{CH}=\right)$; $31 \cdot 8-25 \cdot 7\left(\mathrm{Ar}-\mathrm{CH}_{2} \mathrm{CH}_{2} \mathrm{CH}_{2}-;-\mathrm{OCH}_{2} \mathrm{CH}_{2} \mathrm{CH}_{2} \mathrm{NH}_{2}-;-\mathrm{CH}_{2} \mathrm{CH}_{2} \mathrm{CH}_{2}-\right)$; $22 \cdot 7\left(-\mathrm{CH}_{3} \mathrm{CH}_{2}-\right) ; 14 \cdot 15\left(\mathrm{CH}_{3}-\right)$.

\subsubsection{Synthesis of $N$-propanesulfonic acid-PPA}

$\mathrm{N}$-propanesulfonic acid (PSA)-PPA was also synthesized using the ring-opening reaction. In a typical synthetic procedure, $1: 1 \cdot 1$ mole ratio of PPA ( $2 \mathrm{mmol})$ and PS $(2 \cdot 2 \mathrm{mmol})$ was mixed at room temperature in anhydrous methanol $(25 \mathrm{ml})$ under nitrogen atmosphere and stirred at reflux temperature for $8 \mathrm{~h}$. After cooling to room temperature, the product precipitated. The solution was filtered and washed with methanol and then dried under vacuum. The product was obtained as an orange powder ( $75 \%$ yield) and was analyzed by proton and carbon-13 NMR spectroscopy.

Proton NMR (400 MHz, deuterated chloroform, TMS): $\delta$ (ppm) 6.6-7.2 (m, 4H, aromatic $\mathrm{CH}) ; 4 \cdot 97-5.92(\mathrm{~m}, 4 \cdot 5 \mathrm{H}$, $\left.-\mathrm{CH}_{2} \mathrm{CH}=\mathrm{CHCH}_{2}-; \quad-\mathrm{CH}_{2} \mathrm{CH}=\mathrm{CH}_{2}\right) ; \quad 3.98 \quad(\mathrm{t}, \quad 2 \mathrm{H}$, $\left.-\mathrm{OCH}_{2} \mathrm{CH}_{2} \mathrm{CH}_{2} \mathrm{NH}-\right) ; 3 \cdot 10-3 \cdot 18$ (dd, $\left.4 \mathrm{H},-\mathrm{CH}_{2} \mathrm{NH}-\right) ; 3 \cdot 02$ $\left(\mathrm{t}, 2 \mathrm{H},-\mathrm{CH}_{2} \mathrm{CH}_{2} \mathrm{SO}_{3} \mathrm{H}\right) ; 2 \cdot 7-2 \cdot 86\left(2 \mathrm{H},=\mathrm{CHCH}_{2} \mathrm{CH}=\right) ; 2 \cdot 55(\mathrm{t}$, $\left.2 \mathrm{H}, \mathrm{Ar}-\mathrm{CH}_{2} \mathrm{CH}_{2} \mathrm{CH}_{2}-\right) ; 2 \cdot 27-2 \cdot 35$ (m, $\left.4 \mathrm{H},-\mathrm{CH}_{2} \mathrm{CH}_{2} \mathrm{NH}-\right) ; 2 \cdot 02$ (m, $\left.3 \mathrm{H},=\mathrm{CHCH}_{2} \mathrm{CH}_{2}-\right) ; 1 \cdot 6\left(\mathrm{~m}, 2 \mathrm{H}, \mathrm{Ar}-\mathrm{CH}_{2} \mathrm{CH}_{2} \mathrm{CH}_{2}-\right) ; 1 \cdot 2-1 \cdot 45$ (m, $\left.12 \mathrm{H},-\mathrm{CH}_{2} \mathrm{CH}_{2} \mathrm{CH}_{2}-\right) ; 0 \cdot 86-0.93\left(\mathrm{~m}, 1 \cdot 8 \mathrm{H},-\mathrm{CH}_{2} \mathrm{CH}_{3}\right)$.

Carbon-13 NMR (400 MHz, deuterated chloroform, TMS): $\delta(\mathrm{ppm}) 158.8(1 \mathrm{C}$, aromatic $\mathrm{CH}-\mathrm{O}) ; 144.6(1 \mathrm{C}$, aromatic $\left.\mathrm{C}-\mathrm{CH}_{2}-\right) ; 136 \cdot 8 \quad\left(-\mathrm{CH}_{2} \mathrm{CH}=\mathrm{CH}_{2}\right) ; 130 \cdot 4-126 \cdot 8$ (1C aromatic, $\left.-\mathrm{CH}_{2} \mathrm{CH}=\mathrm{CH}_{2}-\mathrm{CH}_{2} \mathrm{CH}=\mathrm{CHCH}_{2}-\right) ; 120.97$ (1C aromatic); 114.75 (1C aromatic); 111.37 (1C aromatic); $65.38\left(-\mathrm{OCH}_{2} \mathrm{CH}_{2} \mathrm{CH}_{2} \mathrm{NH}-\right)$; $49 \cdot 23\left(-\mathrm{CH}_{2}-\mathrm{S}\right) ; 48 \cdot 3\left(-\mathrm{CH}_{2}-\mathrm{NH}-\right) ; 46.9\left(-\mathrm{OCH}_{2} \mathrm{CH}_{2} \mathrm{CH}_{2} \mathrm{NH}-\right)$; $36 \cdot 1 \quad\left(=\mathrm{CHCH}_{2} \mathrm{CH}=\right) ; \quad 31 \cdot 8-25 \cdot 7 \quad\left(\mathrm{Ar}-\mathrm{CH}_{2} \mathrm{CH}_{2} \mathrm{CH}_{2}-\right.$; $\left.-\mathrm{OCH}_{2} \mathrm{CH}_{2} \mathrm{CH}_{2} \mathrm{NH}_{2}-; \quad-\mathrm{CH}_{2} \mathrm{CH}_{2} \mathrm{CH}_{2}-\right) ; 24.9 \quad\left(-\mathrm{CH}_{2}-\mathrm{CH}_{2} \mathrm{~S}\right)$; $22 \cdot 7\left(-\mathrm{CH}_{3} \mathrm{CH}_{2}-\right) ; 14 \cdot 15\left(\mathrm{CH}_{3}-\right)$.

\subsubsection{Synthesis of PSA-TMAG-PPA}

PSA-TMAG-PPA was synthesized using two procedures.

The first procedure is as follows: $1: 1 \cdot 1$ mole ratio of TMAG-PPA $(1.5 \mathrm{mmol})$ and PS $(1.65 \mathrm{mmol})$ was mixed at room temperature in anhydrous methanol $(20 \mathrm{ml})$ under nitrogen atmosphere and stirred at reflux temperature for $8 \mathrm{~h}$. After cooling to room temperature, the product precipitated. The solution was filtered and washed with methanol and then dried under vacuum. The product was obtained as a yellow solid (62\% yield).

The second procedure is as follows: $1: 1 \cdot 1$ mole ratio of PSA-PPA $(1.5 \mathrm{mmol})$ and TMAGC $(1.65 \mathrm{mmol})$ was mixed at room temperature in anhydrous methanol $(20 \mathrm{ml})$ under nitrogen atmosphere and stirred at reflux temperature for $8 \mathrm{~h}$. After cooling to room temperature, the product precipitated. The solution was filtered, washed with methanol and then dried under vacuum. The product was obtained as a yellow solid ( $92 \%$ yield).

PSA-TMAG-PPA was analyzed by proton and carbon-13 NMR spectroscopy.

Proton NMR (400 MHz, deuterated chloroform, TMS): $\delta$ (ppm) 6.6-7.2 (m, 4H, aromatic $\mathrm{CH}) ; 4.97-5.92(\mathrm{~m}, \quad 4 \cdot 5 \mathrm{H}$, $\left.-\mathrm{CH}_{2} \mathrm{CH}=\mathrm{CHCH}_{2}-;-\mathrm{CH}_{2} \mathrm{CH}=\mathrm{CH}_{2}\right) ; 4.37\left(\mathrm{~m}, 1 \mathrm{H},-\mathrm{CH}_{2} \mathrm{CH}-(\mathrm{OH})\right.$ $\left.\mathrm{CH}_{2}-\right) ; 3.98$ (t, $\left.2 \mathrm{H},-\mathrm{OCH}_{2} \mathrm{CH}_{2} \mathrm{CH}_{2} \mathrm{~N}-\right) ; 3 \cdot 32-3 \cdot 82\left(4 \mathrm{H},-\mathrm{CH}_{2} \mathrm{~N}\right.$ $\left.\left(\mathrm{CH}_{3}\right)_{3},-\mathrm{CH}_{2} \mathrm{CH}_{2} \mathrm{SO}_{3} \mathrm{H}\right) ; 3 \cdot 29\left(\mathrm{~s}, 9 \mathrm{H},-\mathrm{N}\left(\mathrm{CH}_{3}\right)_{3}\right) ; 2 \cdot 60-3 \cdot 00$ (m, $\left.10 \mathrm{H},-\mathrm{CH}_{2} \mathrm{~N}-,-\mathrm{CH}_{2} \mathrm{CH}_{2} \mathrm{SO}_{3} \mathrm{H},=\mathrm{CHCH}_{2} \mathrm{CH}=\right) ; 2 \cdot 55$ (t, $2 \mathrm{H}$, $\left.\mathrm{Ar}-\mathrm{CH}_{2} \mathrm{CH}_{2} \mathrm{CH}_{2}-\right)$; $1.93-2.02 \quad\left(\mathrm{~m}, \quad 5 \mathrm{H}, \quad \mathrm{OCH}_{2} \mathrm{CH}_{2} \mathrm{CH}_{2} \mathrm{NH}_{2}-\right.$, $\left.=\mathrm{CHCH}_{2} \mathrm{CH}_{2}-\right) ; 1 \cdot 6\left(\mathrm{~m}, 2 \mathrm{H}, \mathrm{Ar}-\mathrm{CH}_{2} \mathrm{CH}_{2} \mathrm{CH}_{2}-\right) ; 1 \cdot 2-1 \cdot 45(\mathrm{~m}, 12 \mathrm{H}$, $\left.-\mathrm{CH}_{2} \mathrm{CH}_{2} \mathrm{CH}_{2}-\right) ; 0 \cdot 86-0.93\left(\mathrm{~m}, 1 \cdot 8 \mathrm{H},-\mathrm{CH}_{2} \mathrm{CH}_{3}\right.$ ).

Carbon-13 NMR (400 MHz, deuterated chloroform, TMS): $\delta(\mathrm{ppm}) 158.8(1 \mathrm{C}$, aromatic $\mathrm{CH}-\mathrm{O}) ; 144.6(1 \mathrm{C}$, aromatic $\left.C-\mathrm{CH}_{2}-\right) ; 136 \cdot 8 \quad\left(-\mathrm{CH}_{2} \mathrm{CH}=\mathrm{CH}_{2}\right) ; 130 \cdot 4-126 \cdot 8 \quad(1 \mathrm{C}$ aromatic, $-\mathrm{CH}_{2} \mathrm{CH}=\mathrm{CH}_{2}-\mathrm{CH}_{2} \mathrm{CH}=\mathrm{CHCH}_{2}-$ ); 120.97 (1C aromatic); 114.75 (1C aromatic); $111 \cdot 37$ (1C aromatic); $69 \cdot 25\left(-\mathrm{CH}_{2}-\mathrm{N}\left(\mathrm{CH}_{3}\right)_{2}\right) ; 65 \cdot 38$ $\left(-\mathrm{OCH}_{2} \mathrm{CH}_{2} \mathrm{CH}_{2} \mathrm{~N}-\right) ; 64 \cdot 3 \quad(-\mathrm{CH}-\mathrm{OH}) ; 58.95 \quad\left(-\mathrm{CH}-\mathrm{CH}_{2}-\mathrm{N}-\right)$; $54.63\left(\mathrm{CH}_{3}-\mathrm{N},-\mathrm{CH}_{2}-\mathrm{CH}_{2}-\mathrm{N}-\right) ; 52 \cdot 43\left(-\mathrm{OCH}_{2} \mathrm{CH}_{2} \mathrm{CH}_{2} \mathrm{~N}-\right) ; 49 \cdot 23$ $\left(-\mathrm{CH}_{2}-\mathrm{S}\right) ; 36 \cdot 1 \quad\left(=\mathrm{CHCH}_{2} \mathrm{CH}=\right) ; 31 \cdot 8-25 \cdot 7 \quad\left(\mathrm{Ar}-\mathrm{CH}_{2} \mathrm{CH}_{2} \mathrm{CH}_{2}-\right.$; $\left.-\mathrm{OCH}_{2} \mathrm{CH}_{2} \mathrm{CH}_{2} \mathrm{NH}_{2}-;-\mathrm{CH}_{2} \mathrm{CH}_{2} \mathrm{CH}_{2}-\right) ; 24.9\left(-\mathrm{CH}_{2}-\mathrm{CH}_{2} \mathrm{~S}\right) ; 22 \cdot 7$ $\left(-\mathrm{CH}_{3} \mathrm{CH}_{2}-\right) ; 14 \cdot 15\left(\mathrm{CH}_{3}-\right)$. 


\subsection{Surface tension measurement}

The surface tensions of the surfactant were measured in a $500 \mathrm{mM}$ sodium chloride solution by the pendant drop method using a DataPhysics OCA 15 Pro device.

\subsection{Krafft temperature}

The Krafft temperature was determined as follows. A $0.5 \mathrm{wt} . \%$ sample was dissolved in a sodium chloride solution, and the temperature was raised to $95^{\circ} \mathrm{C}$ to produce a clear solution. Then, the solution was slowly cooled until the appearance of the turbidity that signaled the Krafft point.

\section{Results and discussion}

\subsection{Cardanol-based surfactant synthesis}

The synthesis of three surfactants based on cardanol was reported according to the procedure given in Figure 2. These surfactants are ionic and differ in the nature of the charge of their polar heads
- that is, cationic (TMAG-PPA), anionic (PSA-PPA) and zwitterionic (PSA-TMAG-PPA).

First, PPA was synthesized by nucleophilic substitution of cardanol with chloropropylamine in the presence of a strong base (sodium hydroxide). Then, the primary amine generated was used as the substrate for the ring-opening reactions of TMAGC and PS to obtain TMAG-PPA and PSA-PPA, respectively. Finally, TMAG-PPA and PSA-PPA were coupled with TMAGC and PS, respectively, to give PSA-TMAG-PPA. The structures of the surfactants are confirmed by proton and carbon-13 NMR (Figures 3-6). Moreover, there is no residual propanesultone on the products. Indeed, on all the NMR spectra, the authors observe the absence of the characteristic peaks at $4.27 \mathrm{ppm}$ of $\mathrm{CH}_{2}$ in alpha position relative to sultone function.

The proton NMR spectra of the representative product PPA and cardanol are illustrated in Figure 3. The spectrum of PPA shows

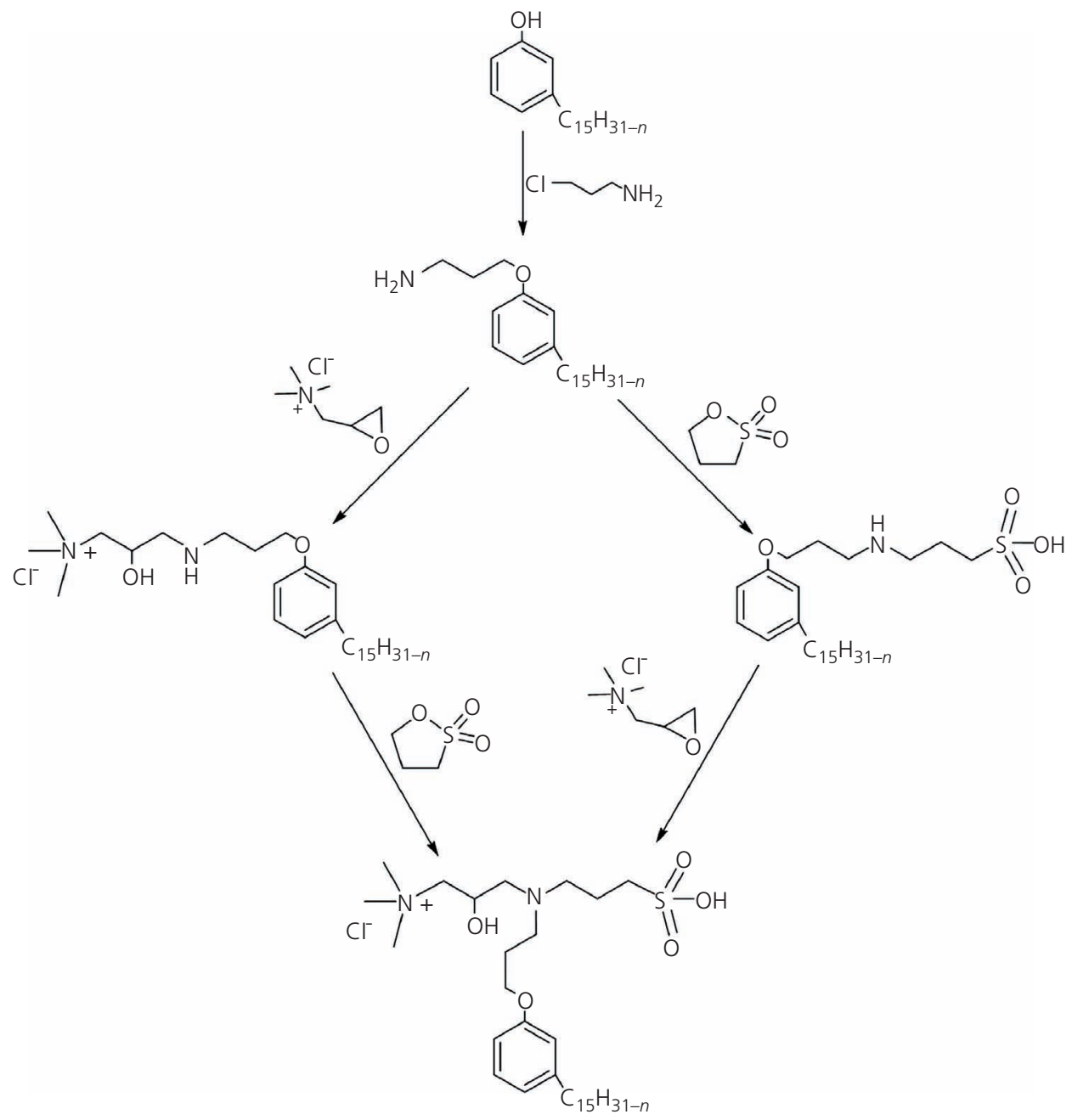

Figure 2. Synthesis protocol and structures of the cardanol-based surfactants: cationic TMAG-PPA, anionic PSA-PPA and zwitterionic PSA-TMAG-PPA 


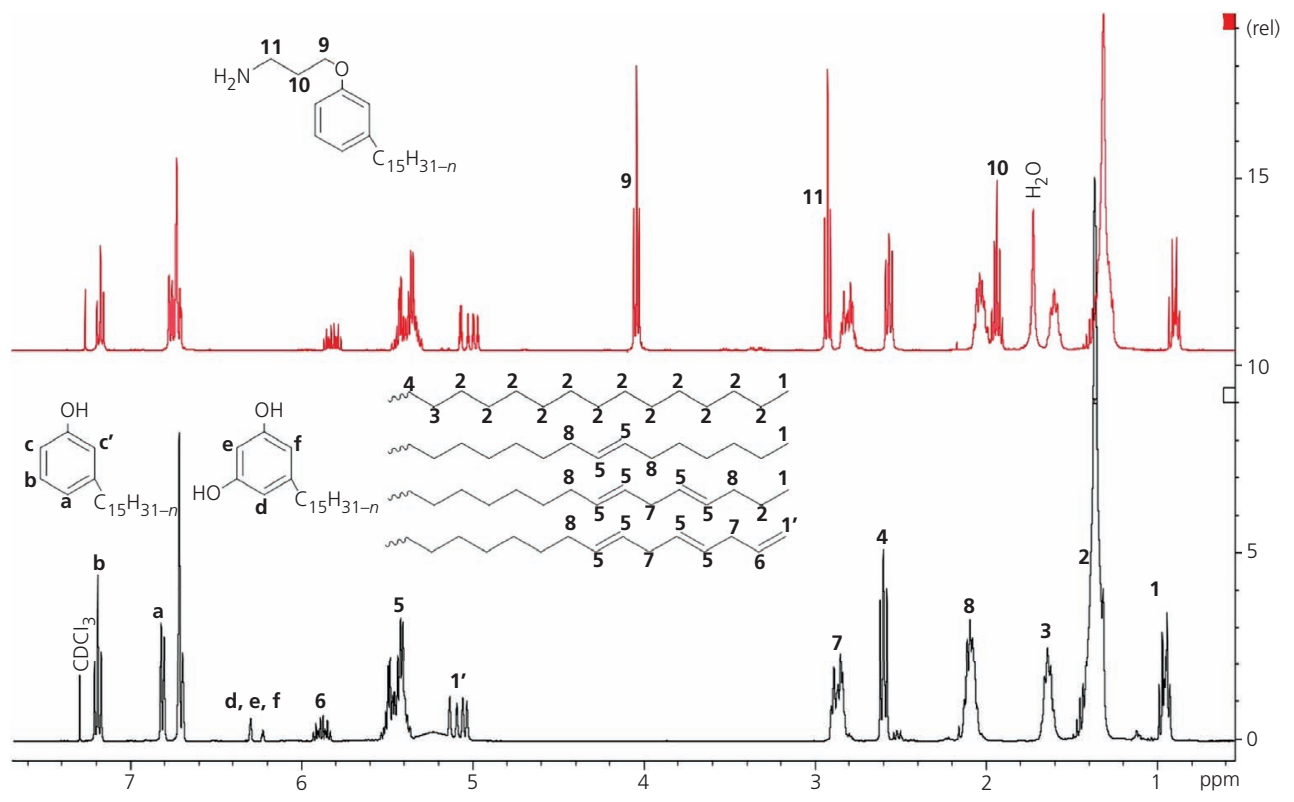

Figure 3. Proton NMR of cardanol and PPA in deuterated chloroform

three new peaks denoted $\mathbf{9}, \mathbf{1 0}$ and $\mathbf{1 1}$ compared to those of cardanol. These peaks correspond to the protons of propylamine grafted on cardanol and all integrate for two protons. Cardol (5\%) was observed on the proton NMR spectrum of cardanol as well as the absence of the product corresponding to its modification with chloropropylamine. This can be explained by the presence of two amines on the modified cardol, making it highly water soluble and remaining in this phase during the purification of the PPA.

The proton NMR spectra of the synthesized surfactants (TMAG-PPA, PSA-PPA and PSA-TMAG-PPA) and PPA are superimposed in Figure 4. The structure of TMAG-PPA

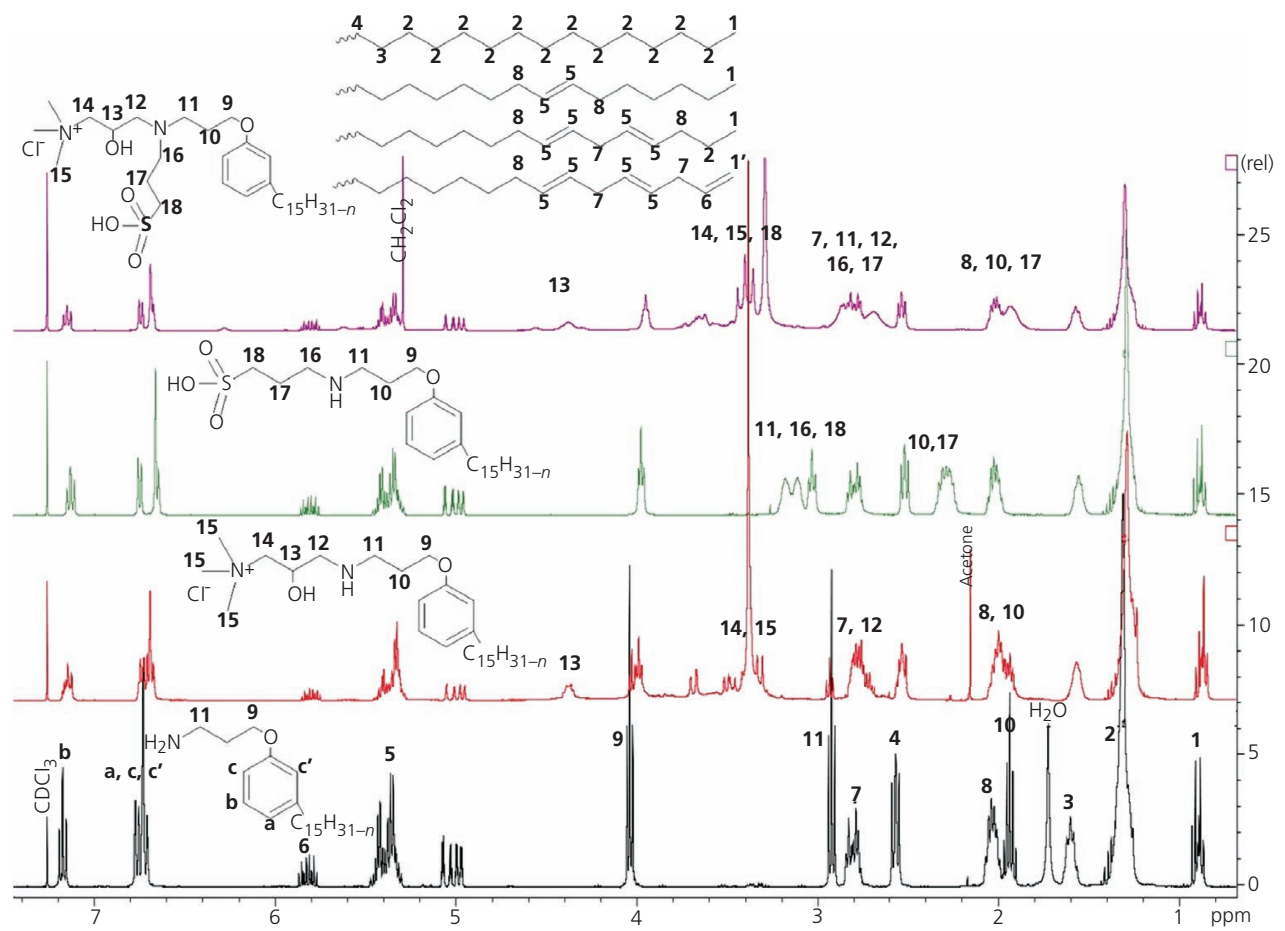

Figure 4. Proton NMR of PPA, TMAG-PPA, PSA-PPA and PSA-TMAG-PPA in deuterated chloroform 
Sustainable cardanol-based ionic surfactants

Faye, Besse, David and Caillol

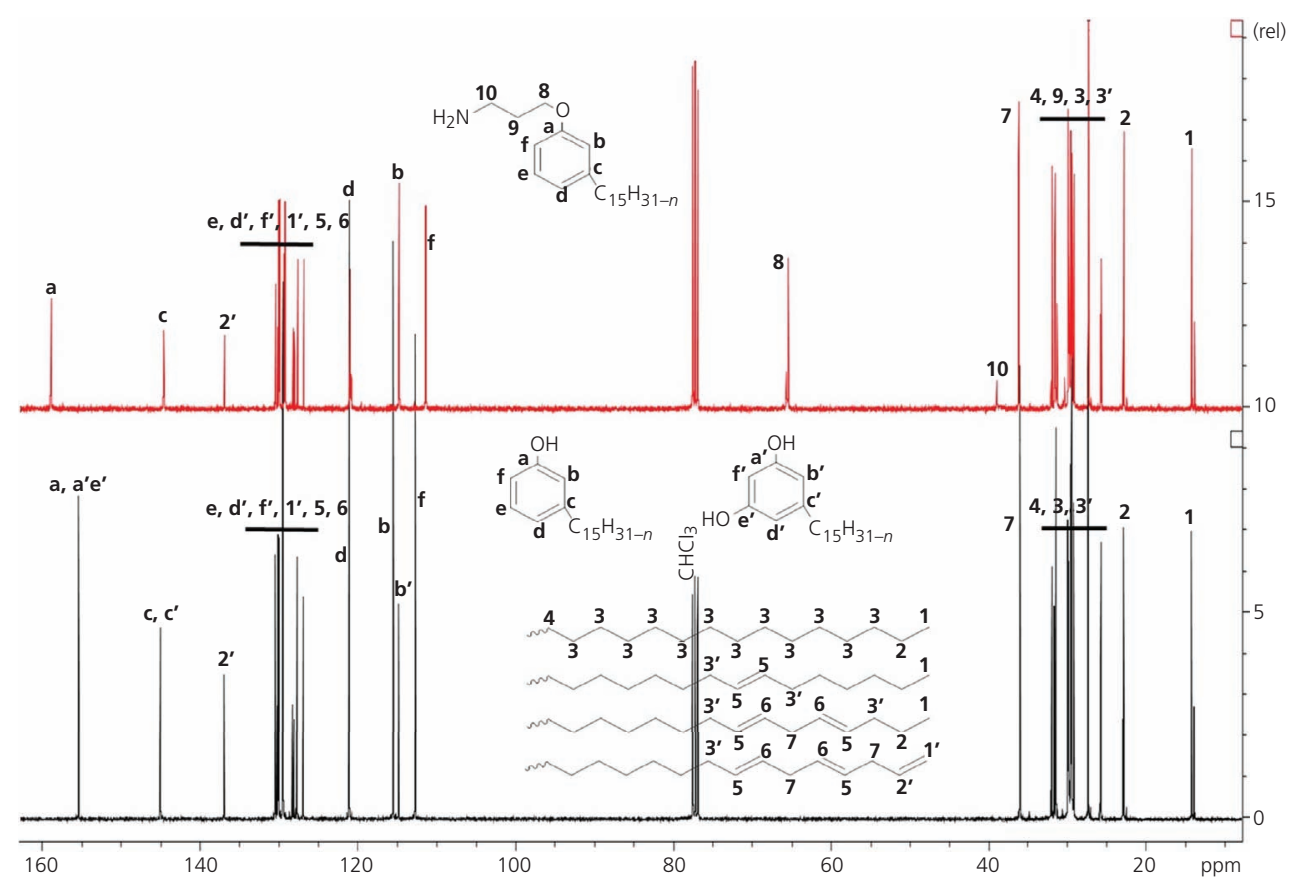

Figure 5. Carbon-13 NMR of cardanol and PPA in deuterated chloroform

was elucidated by protons $\mathbf{1 4}$ and $\mathbf{1 5}$ corresponding, respectively, to the methylene and methyl protons linked to quaternary ammonium and proton $\mathbf{1 3}$ corresponding to the proton of the tertiary carbon with a hydroxyl group. The structure of PSA-PPA was confirmed by the protons denoted 16, 17 and 18, corresponding to the methylene protons contained between sulfur and nitrogen atoms. Amphoteric PSA-TMAG-PPA was elucidated by the same proton contents in

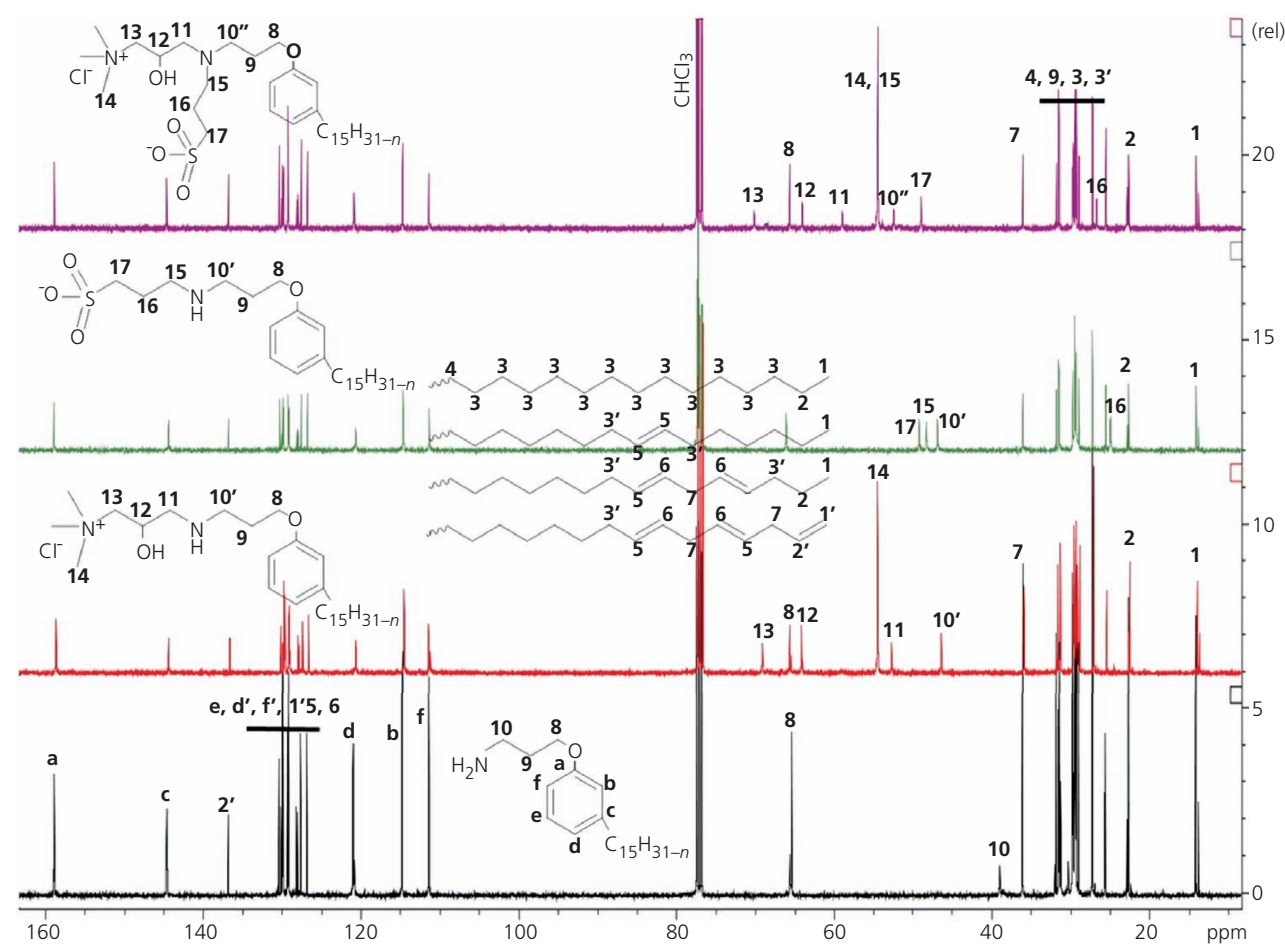

Figure 6. Carbon-13 NMR of PPA, TMAG-PPA, PSA-PPA and PSA-TMAG-PPA in deuterated chloroform 
TMAG-PPA and PSA-PPA with small difference regarding the chemical shifts.

The carbon-13 NMR spectra of the representative product PPA and cardanol are given in Figure 5. The spectrum of PPA shows three new peaks $\mathbf{8 , 9}$ and $\mathbf{1 0}$ compared to those of cardanol. These peaks correspond to the carbons of propylamine grafted on cardanol. Peaks $\mathbf{8}$ and $\mathbf{1 0}(65.5$ and $39 \cdot 1 \mathrm{ppm})$ are separated from the other peaks, while peak 9 is included in some peaks of cardanol. Cardol (5\%) was also observed on the carbon-13 spectrum, as previously mentioned with regard to the carbon-13 NMR spectrum of cardanol. It is characterized by a distinct peak denoted $\mathbf{b}^{\prime}$, which disappears after modification for the reason explained earlier.

Figure 6 shows the superposition of the carbon-13 NMR spectra of the synthesized surfactants (TMAG-PPA, PSA-PPA and PSA-TMAG-PPA) and PPA. The carbon-13 NMR spectrum of TMAG-PPA shows four news peaks denoted 11, 12, 13 and 14, which are well differentiated compared to those of PPA. Peaks $\mathbf{1 3}$ and 14 correspond to the carbons linked to quaternary ammonium; peak $\mathbf{1 2}$ corresponds to the tertiary carbon with a hydroxyl group; and peak $\mathbf{1 1}$ corresponds to the carbon between secondary nitrogen and tertiary carbon. A shift of carbon $\mathbf{1 0}$, which becomes 10", is also observed. This is due to the presence of an $\mathrm{OH}$ group in the $\beta$ of the nitrogen and contributes to confirm the structure of the molecule.

The structure of PSA-PPA was elucidated by the appearance of three new carbon peaks $\mathbf{1 5}, \mathbf{1 6}$ and $\mathbf{1 7}$ compared to those of PPA corresponding to the carbons between sulfur and nitrogen atoms. The shift of carbon $\mathbf{1 0}$ of PPA (10" on the PSA-PPA spectrum) was also noticed.

The spectrum of PSA-TMAG-PPA shows the same carbon peaks as those of both TMAG-PPA and PSA-PPA spectra. It means that there are both sulfonate and ammonium ions in the PSA-TMAG-PPA molecule. Shifts of carbons 10", 11 and $\mathbf{1 5}$ are noted compared to TMAG-PPA and PSA-PPA spectra because the nitrogen in their vicinity has become tertiary nitrogen.

The cardanol-based surfactants synthesized are obtained with very good yields. It is noted that these are lower in the case of couplings with PS because of its moisture sensitivity.

\subsection{Surface activity of the cardanol-based surfactants}

At the surface, the surfactants tend to line up so that the polar head is in contact with water and the hydrophobic part is oriented toward the air. At low concentration, surfactants are mainly present at the water surface. A surface interaction between surfactant molecules lowers the surface tension. As the concentration increases, the surfactants form a full monolayer followed by micelle formation. The concentration at which micelle formation occurs is called the CMC. For concentrations greater than the $\mathrm{CMC}$, the surface tension remains constant.
PSA-TMAG-PPA is poorly soluble as observed by Wang et al. ${ }^{22}$ for sultaines. Their solubility can be improved by adding salt to the solution. Therefore, the surface activity parameters were determined in $500 \mathrm{mM}$ sodium chloride solution. The surface tensions of the surfactants were determined for different concentrations to obtain the $\mathrm{CMC}$ as well as the surface tension at the $\mathrm{CMC}\left(\Upsilon_{\mathrm{CMC}}\right)$.

The variation in surface tension as a function of concentration for the three surfactants in $500 \mathrm{mM}$ sodium chloride at $25^{\circ} \mathrm{C}$ is given in Figure 7. The surface tension decreases with increasing surfactant concentration until becoming constant whatever the concentration is.

It was found that all synthesized cardanol-based surfactants lowered the surface tension. From the curves in Figure 7, the $\mathrm{CMC}$ and the surface tension at this concentration $\left(Y_{\mathrm{CMC}}\right)$ were estimated and reported in Table 1. Among the three surfactants, the zwitterionic PSA-TMAG-PPA has the largest CMC, followed by the cationic TMAG-PPA and, finally, the anionic surfactant PSA-PPA. PSA-TMAG-PPA with two polar heads is highly soluble in sodium chloride solution, which implies that high concentrations are required to reach the CMC.

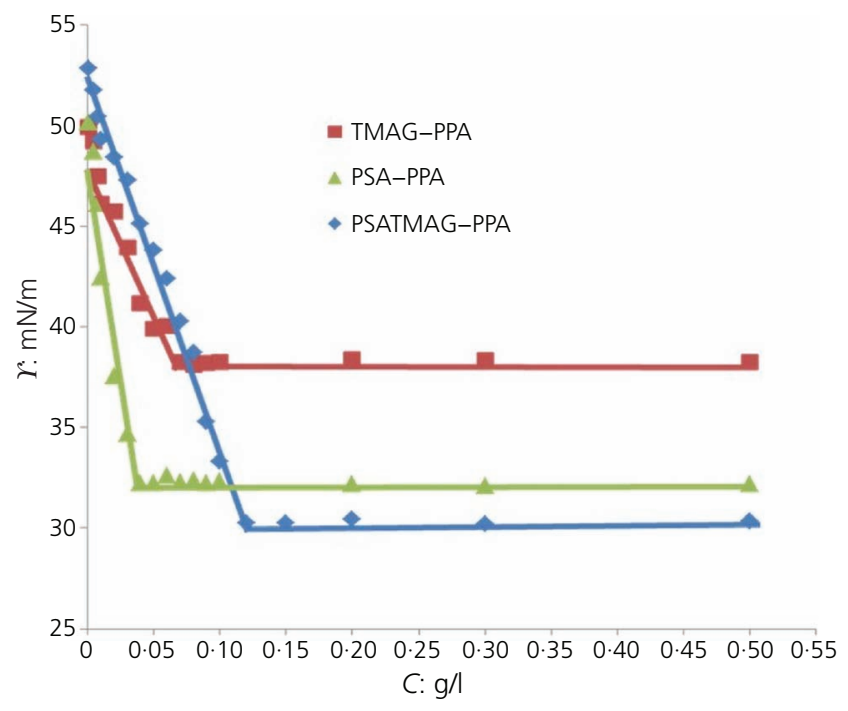

Figure 7. Surface tension plotted as a function of concentration of TMAG-PPA, PSA-PPA and PSA-TMAG-PPA in $500 \mathrm{mM}$ sodium chloride solution at $25^{\circ} \mathrm{C}$

Table 1. Surface activity and rheological parameters of TMAG-PPA, PSA-PPA and PSA-TMAG-PPA in 500 mM sodium chloride at $25^{\circ} \mathrm{C}$

\begin{tabular}{lcc} 
Surfactant & CMC: $\mathbf{m g} / \mathbf{l}$ & $\boldsymbol{r}_{\text {CMc }}: \mathbf{m N} / \mathbf{m}$ \\
\hline TMAG-PPA & 70 & 38.25 \\
PSA-PPA & 40 & $32 \cdot 23$ \\
PSA-TMAG-PPA & 120 & $30 \cdot 29$
\end{tabular}


Table 2. Krafft temperatures of TMAG-PPA, PSA-PPA and PSA-TMAG-PPA as a function of sodium chloride concentration

\begin{tabular}{lcccccc} 
& \multicolumn{5}{c}{ Sodium chloride } \\
\cline { 2 - 6 } & $0 \mathrm{mM}$ & $50 \mathrm{mM}$ & $100 \mathrm{mM}$ & $250 \mathrm{mM}$ & $500 \mathrm{mM}$ \\
\hline TMAG-PPA: ${ }^{\circ} \mathrm{C}$ & 18 & 18 & 16 & 14 & 11 \\
PSA-PPA: ${ }^{\circ} \mathrm{C}$ & - & - & 64 & 37 & 20 \\
PSA-TMAG-PPA: ${ }^{\circ} \mathrm{C}$ & - & 13 & 4 & $<0$ & $<0$
\end{tabular}

—, the surfactants cannot be solubilized in boiling water with this amount of sodium chloride

PSA-TMAG-PPA has the minimum surface tension value $(30 \cdot 29 \mathrm{mN} / \mathrm{m})$, which indicates that the zwitterionic surfactant has a higher surface activity compared with the anionic and the cationic surfactants as expected. But note that there is no great difference in the equilibrium surface tensions. This means that the nature of the hydrophilic part has no significant influence on the surface tension. The three surfactants have the same hydrophobic part and differ only in their polar head which is in contact with the aqueous solution. Therefore, the three different surfactants have similar packing conformations at the air-water interface. ${ }^{22,23}$

\subsection{Krafft temperature of the cardanol-based surfactants per different sodium chloride concentration}

An important characteristic feature of ionic surfactants is their tendency to precipitate from aqueous solutions as solid hydrates. The solubility parameter for which the hydrated solid agent is in equilibrium with and transforms in liquid micellar phase is known as the Krafft point. The temperature at which the solubilization of the undissociated molecules by micelles takes place is termed as 'Krafft temperature' $\left(T_{\mathrm{K}}\right) \cdot{ }^{24,25}$ During this process, the solubility increases sharply with the increase in temperature and a temperature is reached when the solubility is equal to the CMC and micellization takes place.

The $T_{\mathrm{K}}$ values of the surfactants were determined in different sodium chloride solutions following the procedure described in Section 2. The $T_{\mathrm{K}}$ values obtained when increasing the sodium chloride concentration are summarized in Table 2.

The sodium chloride concentration has no influence on the Krafft temperature of TMAG-PPA. On the other hand, its effect is very significant for both PSA-PPA and PSA-TMAG-PPA. This result is in accordance with those of $\mathrm{Chu}$ and $\mathrm{Feng}^{26}$ for sulfoamidobetaine. This is explained by solubility of TMAG-PPA in pure water, whereas the other two surfactants are soluble only in salt solution. The higher the concentration of sodium chloride, the more soluble PSA-PPA and PSA-TMAG-PPA are, and therefore, their Krafft temperatures decrease. Due to its structure, the zwitterionic PSA-TMAG-PPA requires less salt to solubilize, which makes it soluble in $50 \mathrm{mM}$ sodium chloride solution, unlike PSA-PPA. The Krafft temperature of PSA-TMAG-PPA is therefore naturally lower than that of PSA-PPA.

Compared to the results obtained by $\mathrm{Chu}$ and $\mathrm{Feng}^{26}$ in the case of sulfobetaines, zwitterionic sulfobetaine PSA-TMAG-PPA has lower Krafft temperatures while the compound is made of a highly hydrophobic part (16 aliphatic carbons) for sodium chloride concentrations greater than $50 \mathrm{mM}$. Whatever the concentration of salt, its Krafft temperature is lower than those of the Chu and Feng ${ }^{26}$ molecules with more than 16 carbons for the hydrophobic tail. This indicates that PSA-TMAG-PPA is more soluble in salt media despite that the presence of an aromatic cycle in this zwitterion surfactant increases the hydrophobicity of the tail. This improved solubility may be due to the different configuration of the polar heads. For conventional sulfobetaines, propanesulfonate is bound to the quaternary ammonium, ${ }^{22,26}$ whereas in this design, the ammonium and sulfonate functions are not related. This configuration confers to the molecule a larger polar head, which increases its solubility.

\section{Conclusion}

In addition to new cationic and anionic cardanol-based surfactants, the authors synthesized an innovative cardanol-based zwiterrionic surfactant. All the structures of the surfactants disclosed herein were elucidated by NMR spectroscopy (proton, carbon-13). These structures can be sustainable alternatives to alkylbenzene surfactants, which are among the most widely used surfactants. The addition of sodium chloride decreases the Krafft temperature of the anionic and zwitterionic surfactants and increases their solubility in water. Without sodium chloride, the ammonium and sulfonate of the zwitterionic surfactant are organized to form a pair of ions, which leads to a small polar radius, a consequence of poor solubility. By adding salt, the ion pair is broken and two new pairs of ions are formed, which enlarges the hydrophilic ray and improves the solubility.

The zwitterionic surfactant exhibits a higher CMC, lower Krafft temperatures and lower surface tension than the cationic and anionic surfactants, as expected. It is also noted that despite that a carbon chain is supposed to be more hydrophobic, the presence of a larger polar head confers to the zwitterionic PSA-TMAG-PPA a larger $\mathrm{CMC}$ and, hence, higher solubility and smaller Krafft temperatures compared to those of conventional sulfobetaines. These surfactants could be interestingly used in various applications, particularly in anionic or cationic emulsion polymerization for the synthesis of styrene-acrylate latex.

\section{REFERENCES}

1. Yang XH, Wang ZM, Jing F, Hu LH and Zhou YH (2014) A brief review of cardanol-based surfactants. Applied Mechanics and Materials 483: 83-87.

2. Gozlan C, Deruer E, Duclos MC et al. (2016) Preparation of amphiphilic sorbitan monoethers through hydrogenolysis of sorbitan 
acetals and evaluation as bio-based surfactants. Green Chemistry 18(7): 1994-2004.

3. Wang R, Luo Y, Cheng CJ et al. (2016) Syntheses of cardanol-based cationic surfactants and their use in emulsion polymerisation. Chemical Papers 70(9): 1218-1227.

4. Voirin C, Caillol S, Sadavarte NV et al. (2014) Functionalization of cardanol: towards biobased polymers and additives. Polymer Chemistry 5(9): 3142-3162.

5. Mohapatra S and Nando GB (2014) Cardanol: a green substitute for aromatic oil as a plasticizer in natural rubber. RSC Advances 4(30): $15406-15418$.

6. More AS, Pasale SK and Wadgaonkar PP (2010) Synthesis and characterization of polyamides containing pendant pentadecyl chains. European Polymer Journal 46(3): 557-567.

7. Jaillet F, Darroman E, Ratsimihety A et al. (2014) New biobased epoxy materials from cardanol. European Journal of Lipid Science and Technology 116(1): 63-73.

8. Bloise E, Becerra-Herrera M, Mele G et al. (2014) Sustainable preparation of cardanol-based nanocarriers with embedded natural phenolic compounds. ACS Sustainable Chemistry \& Engineering 2(5): 1299-1304.

9. Goncalves RV, Zanini ML, Malmonge JA, Bonnaud L and Basso NRD (2016) Pristine cardanol as biobased dopant for polyaniline. Materials Letters 185: 327-330.

10. Tyman JHP and Bruce IE (2003) Synthesis and characterization of polyethoxylate surfactants derived from phenolic lipids. Journal of Surfactants and Detergents 6(4): 291-297.

11. Tyman JHP and Bruce IE (2004) Surfactant properties and biodegradation of polyethoxylates from phenolic lipids. Journal of Surfactants and Detergents 7(2): 169-173.

12. Scorzza C, Nieves J, Vejar F and Bullon J (2010) Synthesis and physicochemical characterization of anionic surfactants derived from cashew nut shell oil. Journal of Surfactants and Detergents 13(1): 27-31.

13. Kattimuttathu SI, Foerst G, Schubert R and Bartsch E (2012) Synthesis and micellization properties of new anionic reactive surfactants based on hydrogenated cardanol. Journal of Surfactants and Detergents 15(2): 207-215.

14. Anilkumar P and Jayakannan M (2006) New renewable resource amphiphilic molecular design for size-controlled and highly ordered polyaniline nanofibers. Langmuir 22(13): 5952-5957.
15. Bruce IE, Mehta L, Porter MJ, Stein BK and Tyman JHP (2009) Anionic surfactants synthesised from replenishable phenolic lipids. Journal of Surfactants and Detergents 12(4): 337-344.

16. Peungjitton $P$, Sangvanich $P$, Pornpakakul S, Petsom A and Roengsumran S (2009) Sodium cardanol sulfonate surfactant from cashew nut shell liquid. Journal of Surfactants and Detergents 12(2) 85-89.

17. Avellar IGJ, Godoy K and de Magalhães GC (2000) New quaternary ammonium salts derived from cardanol and their use as phase transfer catalyst. Journal of the Brazilian Chemical Society 11(1): 22-26.

18. Verge P, Fouquet T, Barrere C et al. (2013) Organomodification of sepiolite clay using bio-sourced surfactants: compatibilization and dispersion into epoxy thermosets for properties enhancement. Composites Science and Technology 79: 126-132.

19. McLachlan AA and Marangoni DG (2006) Interactions between zwitterionic and conventional anionic and cationic surfactants. Journal of Colloid and Interface Science 295(1): 243-248.

20. Munoz M, Rodriguez A, Graciani MD and Moya ML (2004) Conductometric, surface tension, and kinetic studies in mixed SDSTween 20 and SDS-SB3-12 micellar solutions. Langmuir 20(25): 10858-10867.

21. Liu Q, Dong MZ, Ma SZ and Tu Y (2007) Surfactant enhanced alkaline flooding for Western Canadian heavy oil recovery. Colloids and Surfaces A 293(1-3): 63-71.

22. Wang YJ, Zhang YM, Liu XL et al. (2014) Effect of a hydrophilic head group on Krafft temperature, surface activities and rheological behaviors of erucyl amidobetaines. Journal of Surfactants and Detergents 17(2): 295-301.

23. Alexandridis P, Athanassiou V, Fukuda S and Hatton TA (1994) Surface-activity of poly(ethylene oxide)-block-poly(propylene oxide)block-poly(ethylene oxide) copolymers. Langmuir 10(8): 2604-2612.

24. Bakshi MS and Sood R (2004) Cationic surfactant-poly(amido amine) dendrimer interactions studied by Krafft temperature measurements. Colloids and Surfaces A 233(1-3): 203-210.

25. Vautier-Giongo $C$ and Bales BL (2003) Estimate of the ionization degree of ionic micelles based on Krafft temperature measurements. Journal of Physical Chemistry B 107(23): 5398-5403.

26. Chu ZL and Feng YJ (2012) Empirical correlations between Krafft temperature and tail length for amidosulfobetaine surfactants in the presence of inorganic salt. Langmuir 28(2): 1175-1181.

\section{How can you contribute?}

To discuss this paper, please submit up to 500 words to the journal office at journal@ice.org.uk. Your contribution will be forwarded to the author(s) for a reply and, if considered appropriate by the editor-in-chief, it will be published as a discussion in a future issue of the journal.

ICE Science journals rely entirely on contributions from the field of materials science and engineering. Information about how to submit your paper online is available at www.icevirtuallibrary.com/page/authors, where you will also find detailed author guidelines. 